\title{
Energy dissipating devices in falling rock protection barriers
}

\author{
Castanon-Jano, L., Blanco-Fernandez, E., Castro-Fresno, D., Ballester-Muñoz, F. \\ GITECO (Construction Technology Applied Research Group), Civil Engineering School, University of Cantabria, Santander, Spain
}

\begin{abstract}
Rockfall is a phenomenon which, when uncontrolled, may cause extensive material damage and personal injury. One of the structures used to avoid accidents caused by debris flows or rockfalls is flexible barriers. The energy dissipating devices which absorb the energy generated by rock impact and reduce the mechanical stresses in the rest of the elements of the structure are an essential part of these kinds of structures. This document proposes an overview of the performance of energy dissipating devices, as well as of the role that they fulfil in the barrier. Furthermore, a compilation and a description of the dissipating elements found in literature are proposed. Additionally, an analysis has been performed of the aspects taken into account in the design, such as experimental (quasi-static and dynamic) tests observing the variation of the behaviour curve depending on the test speed and numerical simulations by means of several finite element software packages.
\end{abstract}

Keywords: rockfall flexible barrier, energy dissipating device, dynamic behaviour

\section{Introduction}

Falling rock events can cause dangerous situations, especially when they occur close to towns, roads, railways or places with human transit. In such cases, material and personal damage must be avoided by placing protective systems. A wide variety of slope protection techniques exists, which cover different ranges of energy absorption and are suitable for landslides of different character (Chen et al. 2013; Descoeudres 1988; Descoeudres et al. 1999; Volkwein et al. 2011b).

Traditionally, the design of rockfall protection systems was based on the rigidity and resistance of their components in order to provide a long useful life. Rigid walls were used (Peila et al. 2007), covering an absorption of energy up to $50 \mathrm{~kJ}$ (Volkwein et al. 2011a). Rockfall galleries (Schellenberg et al. 2009) are rigid structures designed for a high frequency -more than once a week (Lopez Quijada 2007)-of medium magnitude events, with a maximum absorbed energy of around $2000 \mathrm{~kJ}$ (Volkwein et al. 2011a). Both rigid walls and rockfall galleries require large volumes of material or extensive placement. The problem appears when the rocks fall from areas which are difficult to reach, or when the natural conditions do not allow the building of large, complex structures to prevent damages. The development of flexible barriers (Fig. 1) addressed this point, covering a wide range of energy absorption, from $150 \mathrm{~kJ}$ (Lopez Quijada 2007) up to 8000 kJ (Escallón et al. 2013). They consist of a steel mesh surrounded by steel cables that are connected to steel posts, keeping the mesh extended. When a rock impacts in the mesh, loads are transmitted through the cables up to the anchorages on the ground. First designs had embedded posts, and could be inserted at the top of concrete walls, resulting in low capacity protection (de Miranda et al. 2015). Displacement of some of the barrier components with the rock until it stopped was enabled, allowing rotation at the base of the posts, using upslope and lateral cables in order to keep the barrier in its position. The increase in flexibility results in a higher load actuation time (known as braking time) and hence, a reduction of the maximum load on all the components of the structure. Energy dissipaters are an essential device in this context, due to the increase in the energy absorption capacity with respect to non-braking barriers. The maximum absorbed energy of a barrier without brakes is $100 \mathrm{~kJ}$ (Muraishi et al. 2005). The adding of brakes to the rockfall protection systems allowed the development of high energy absorption barriers with a maximum value of $8500 \mathrm{~kJ}$ (Maccaferri) nowadays.

Energy dissipating devices may be defined as the mechanisms incorporated into the flexible barrier system to absorb internal energy, helping to reduce stresses within the structure in a rock impact. These devices 
transform the kinetic and potential energy of the falling materials into deformation energy, fracture or heat generated by friction. These elements can also be called brake devices, brake elements or brakes.

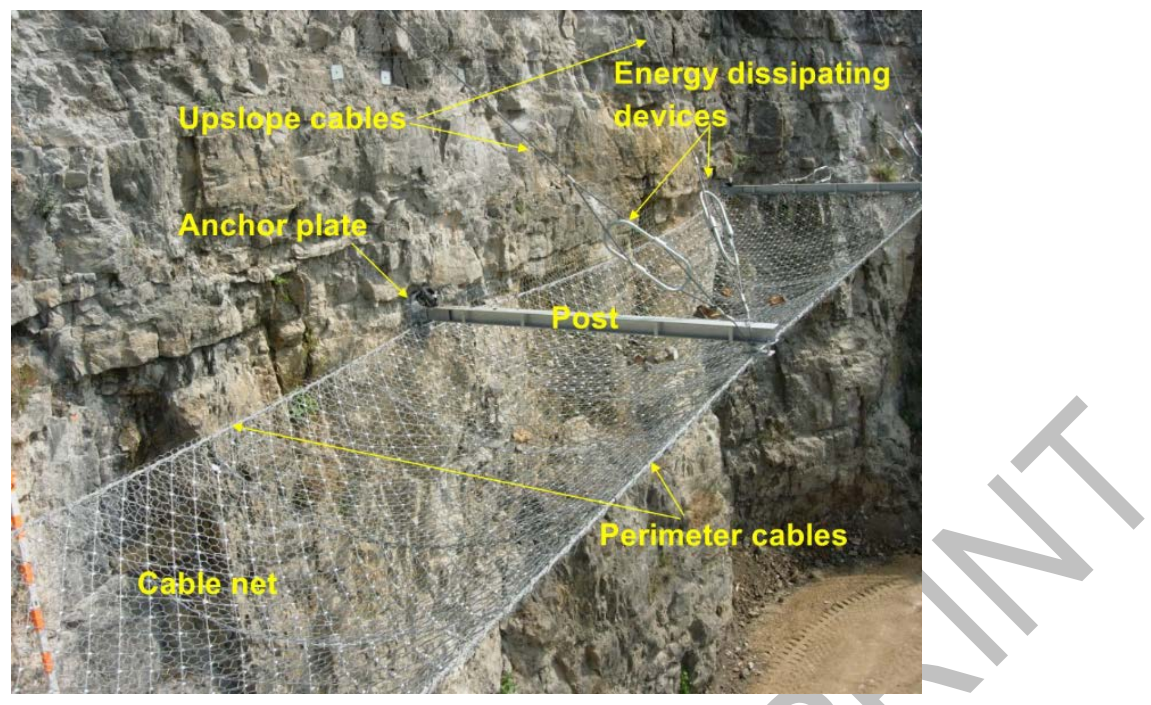

Fig. 1. Flexible barrier components. The interception structure receives the impact of the rock. It is usually made of cable or ring nets and a secondary layer of a wire mesh with finer gap size to collect smaller rocks. Loads are transmitted through the perimeter, upslope and lateral cables to the ground.

Some predecessors of the current energy dissipater were designed to make the barrier more flexible. These devices elastically deform while tension exists, recovering their shape when it ends (López Quijada 2007). They are wrongly called energy dissipaters because they do not contribute to dissipation, but absorb the energy within the elastic range of deformation. The energy is recovered by the system when the components retake their original shape. This solution involves a reduction in the stresses in the cables where the device is connected until the end of its stroke. Then, the cable begins to load according to its real (and stiffer) loaddisplacement curve. Figure 2 shows a device based on the compression of its neoprene components. Post bases are another option to place this type of devices (Fig. 2b). The anchoring of the posts is freed by the addition of the device. A small degree of rotation is allowed in the perpendicular plane of the barrier, recoverable a posteriori.
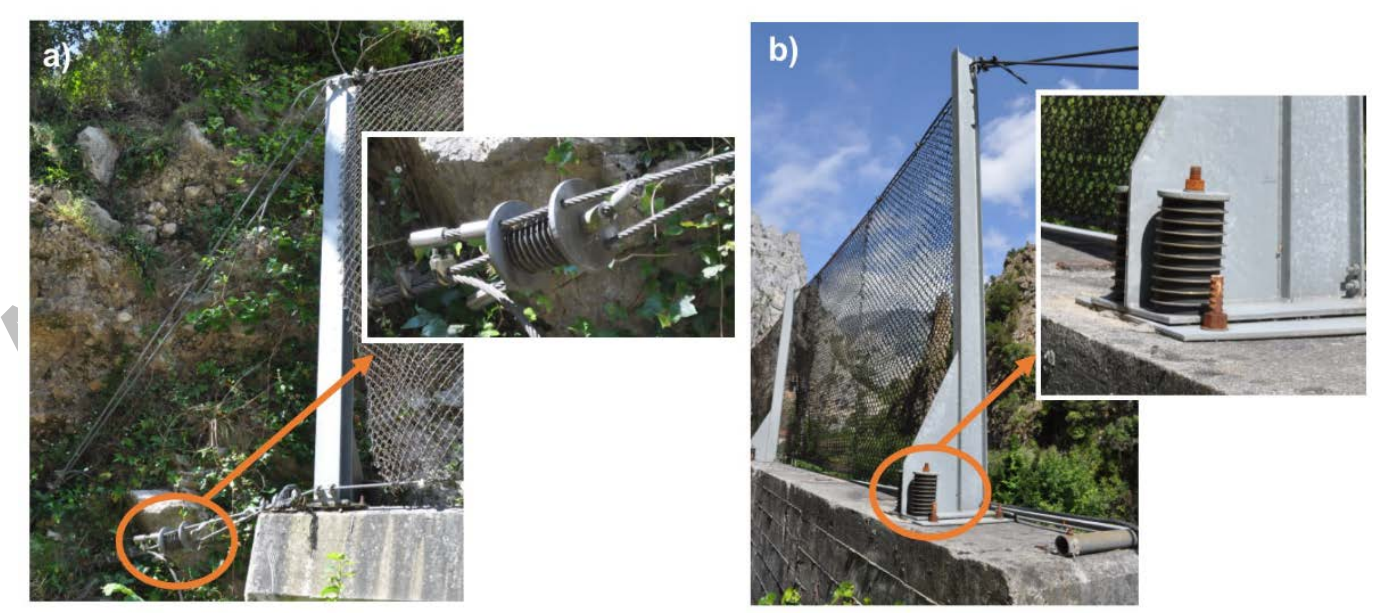

Fig. 2. Elastic devices a) in lateral cables, reducing stresses in the connecting components, and b) in a post base, allowing a small rotation and reducing the stiffness of the barrier.

It is considered that in 1975 the first "real" brake element was designed and installed in a dynamic barrier by Brugg Cable Products (Smith et al., 1990). Since then, numerous devices have been invented to improve the barrier behaviour. In total 174 patent families (inventions) have been found describing a new energy 
dissipating device or a new barrier in which these devices play an important role. The 174 patent families represent 120 different assignees, Fatzer (a company of the Brugg group) and Pfeifer Isofer being the most significant both in numbers of applications and granted IPR (Intelectual Property Rights) (Verbeke 2015). The most representative brake devices will be described in this paper. The selection of the brakes will be based on knowledge of their behaviour and specific data about energy absorption.

Nowadays, the design and evaluation of new brakes can be accomplished with the help of two different procedures. The first, based on experimental tests, gives essential information about the behaviour curve of the prototype. The most recent tests are dynamic in order to make the brake work in a similar way to real conditions. This paper provides an overview of all experimental test types performed on brakes, and presents a comparative analysis of the available data about brakes, comprising activation force, mean running force and dissipated energy. The second tool to help in brake design is numerical simulation. Geometrical optimization can be carried out with this technique, as well as an analysis of the effect of the brakes' position on the complete barrier behaviour. A compilation of all the approaches enables us to see the great potential of computational tools.

\section{Description of the existing brakes}

Brake elements currently on the market are grouped in 4 classes according to the way they dissipate energy:

- Brake elements by pure friction

- Brake elements by partial failure

- Brake elements by plastic deformation

- Brake elements by mixed friction/plastic deformation

\subsection{Brake elements by pure friction}

They were the first brakes to be invented due to their simplicity, mainly using the support cables of the barrier and friction clamps connected to a plane surface. Pressure is applied on the clamp by the bolts' torque.

The brake in Figure 3a (Smith et al. 1990) consists of a looped cable. The cross of the cable is pressed by a friction clamp with four bolts. The EI brake (Smith et al., 1990) in Figure 3b comprises a clamp where two cables go through. Two ends of the cables are connected to the lateral or upslope anchor and to the free end of the post. The other ends of the two cables are free to allow the friction process up to a limited length. The brake in Figure 3c (Trad et al. 2013) consists of the compression of a cable on a plate through a clamp with two bolts. This cable is fixed at one end to the post and the other end is free to allow slippage in the clamp. In order to ensure the transmission of force to the ground, the plate is connected to another cable that is fixed to an anchor. The brake in Figure 3d uses the same dissipation mechanism as the previous one, substituting the fixed connection of the cable in the plate by another clamp+bolt system (Peila et al. 1998). In this way, both the cables coming from the post and the anchor are able to slide dissipating energy.

A disadvantage of this kind of brakes is the use of the support and connection cables in the braking mechanism, which could bring on local failures. Furthermore, the inaccuracy of the bolts' torque can lead to obstruction of the cables or a poor friction dissipation process. 

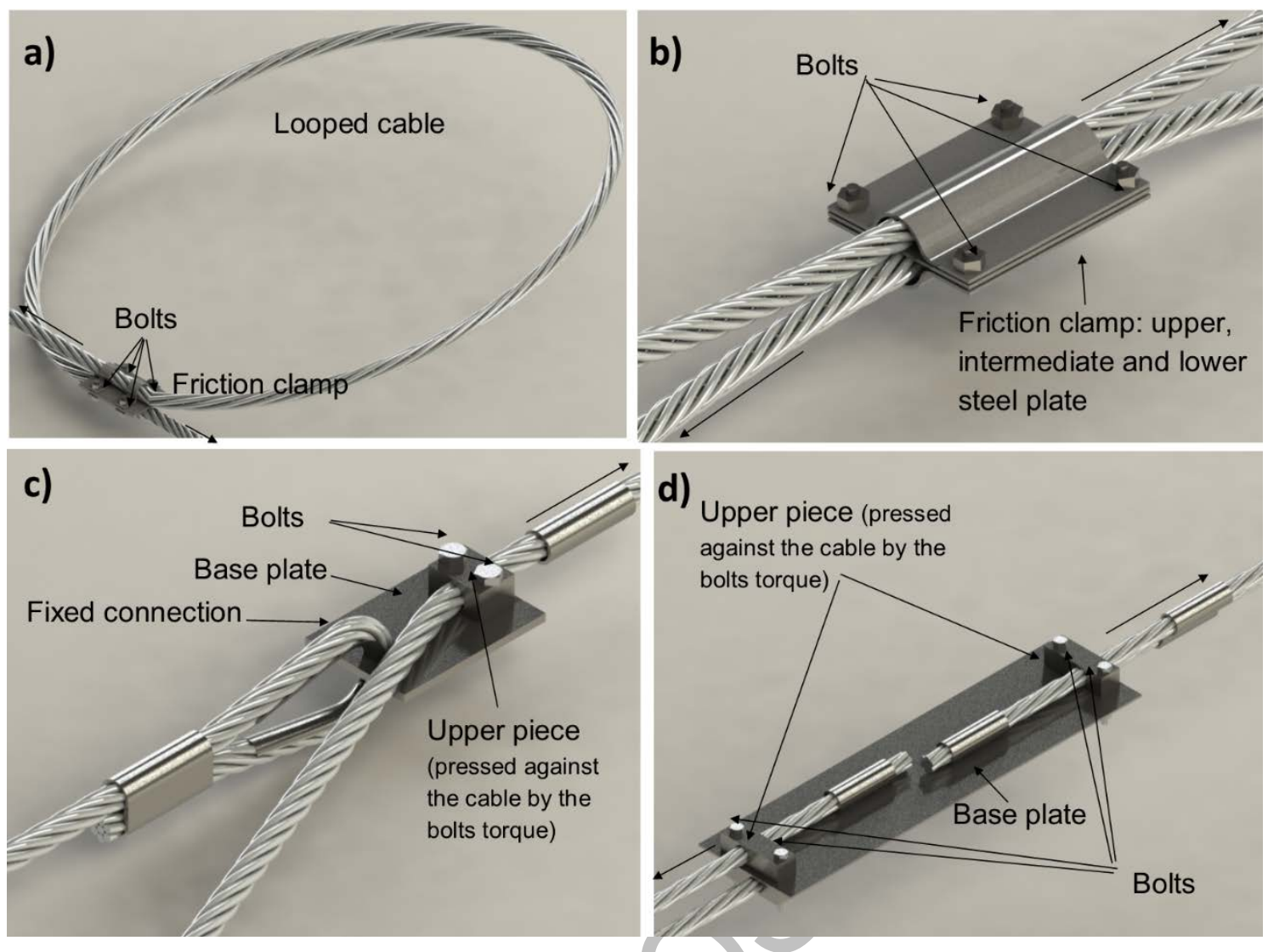

Fig.3. Friction brakes: A) loop brake (Brugg AG), B) two plates compression (EI Enterprise Industrielle), C) simple friction brake (G.T.S.) and D) double friction brake (E.L.I.T.E TUBOSIDER).

\subsection{Brake elements by plastic deformation}

The energy absorption of this kind of brakes is based on the non-recoverable deformation of some of their components.

A simple system can be seen in Figure 4 (Von Allmen HP 2004). It includes a metal spiral connected at its ends to the cables by shackles. When tension is created in the cables, the spiral stretches deforming plastically.

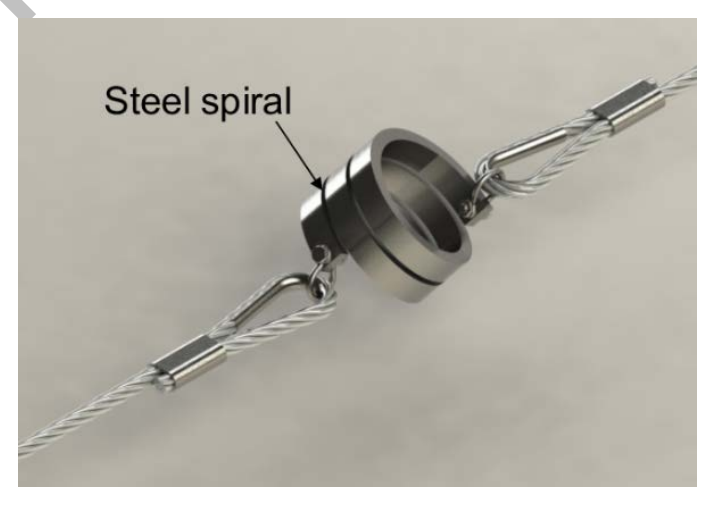

Fig. 4. Spiral brake element by deformation (TRUMER).

\subsection{Brake elements by partial failure}

This type of brake elements is the least common. The first, illustrated in Figure 5a, is comprised of a tube within which two cables move in opposite directions from each side (López Quijada 2007). These drag a 
sharpened piece, which when entering in the tube divides it and dissipates energy. The work performed by the forces in the brake element to absorb kinetic energy is the same as the cut resistance of the tube multiplied by the cut length. The disadvantage with the system is that great opposition to the cut may trigger cable rupture or tube deformation by buckling. On the other hand, low opposition to the cut could cause a quick working of the brake and the energy dissipation would be lower than expected. The second brake shown (Fig. 5b) consists of a series of cables connected in parallel, each one longer than the previous one (Thomel L. 1998). The working sequence is as follows: the shortest cable is the only one bearing the loads induced by the rockfall. When the ultimate strength is overcome, the cable breaks and the load is transmitted to the cable immediately following in length, which will in turn break when, once again, the load becomes greater than can be tolerated by the cable. This cycle goes on while the load can be supported by one of the cables.
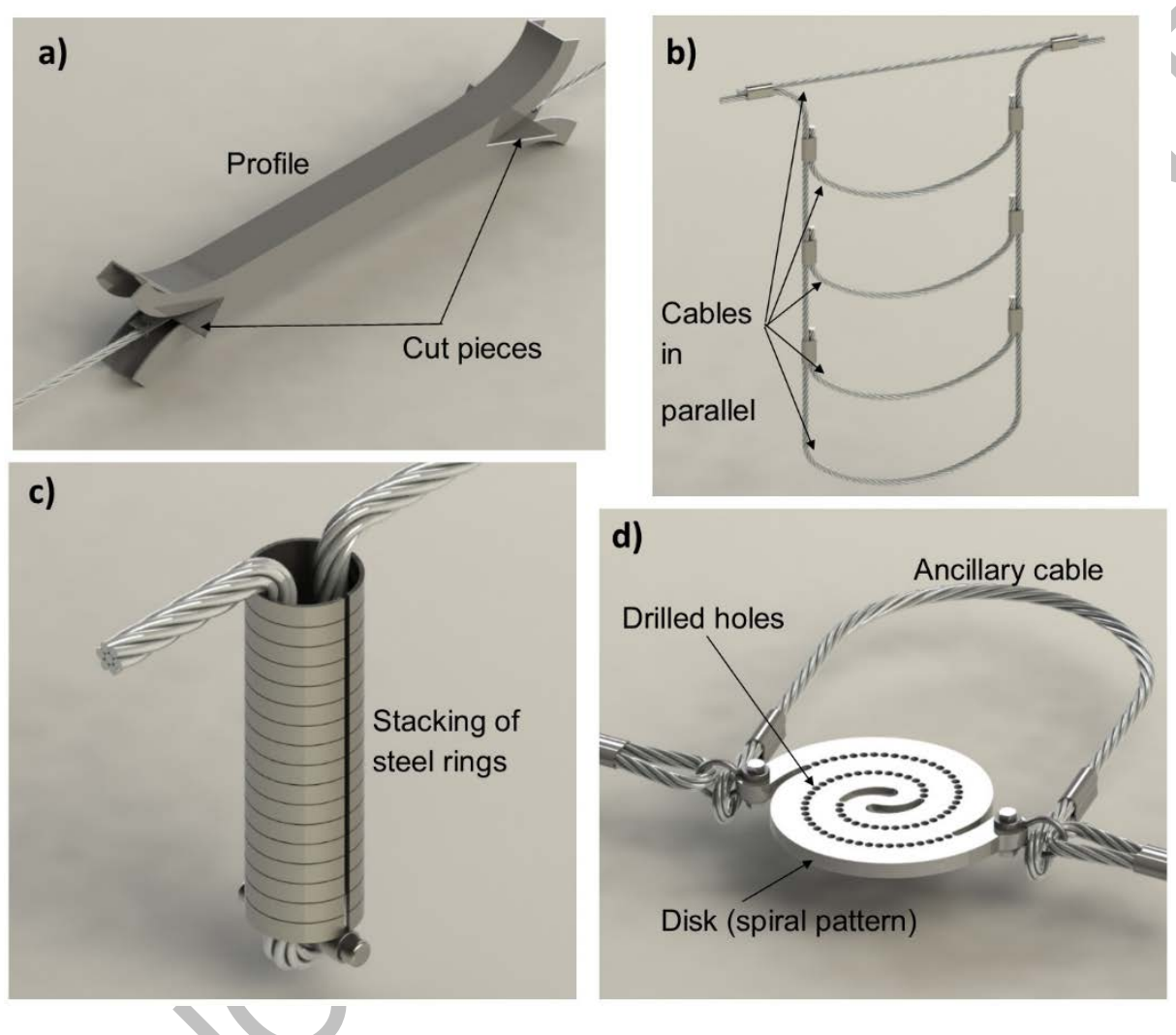

Fig. 5. Brake elements by partial failure: a) by tube cutting (Sisyphe) b) by cables in parallel (Sol Systemes), c) metal disks’ case (Tecnap Sàrl) and d) Pfeifer brake system (Pfeifer).

The brake in Figure 5c is composed of a stack of steel rings. The cable is folded, introduced through one end of the stack and attached at the opposite end around a pivot. The cable's traction leads to compression and plastic deformation of each of the metal rings, and then to their breaking sequentially (Moreillon A. 2006). The load tolerated by the brake will depend on the metal rings' size and the maximum elongation will be proportional to the number of rings placed together forming the casing. The most recent dissipater in this group is shown in Figure 5d (Fulde et al. 2013). It comprises a disc with a series of drilled holes in a spiral pattern. When the cables transmit the force to the brake, the material between the holes deforms plastically, one after another, until failure. At the same time, the two arms generated by these breaks tighten obtaining a single strip when the dissipater is fully elongated.

Brake elements by partial failure can be dangerous due to the possibility of rupture in unexpected zones of the brake (Fulde et al. 2013). The preservation of brake integrity is essential. Otherwise the connections of the free end of posts with the anchors would fail leaving the barrier inoperable. Metal disk brakes (Fig. 7c) are installed in a continuous cable where there are no discontinuities, therefore, when all the disks break the cable bears the loads preserving the barrier integrity. If continuity of the cable is not possible, a good solution is to add a parallel cable attached to both ends of the brake, as has been done in the Pfeifer brake (Fig. 7d). The cable in parallel included in the Pfeifer brake has the same or higher resistance to the cable 
in which the brake is installed and the same length as the maximum elongation the brake can stand. In this way, if the brake collapses, the auxiliary cable will preserve the brake element integrity.

\subsection{Mixed brake elements: friction/deformation}

The first brake element with these characteristics was created by the Tubosider company (Peila et al. 1998). It is composed of a metal tube through which cables pass from both ends via a plug in each end (figure 6a). When the load is transmitted to the brake, the cables move in opposite directions taking the plugs with them. The energy absorption occurs both by the plugs' friction and by the tube's buckling. A disadvantage of this type of brake is the possibility of blocking of the plugs and reduction in the expected absorbed energy.

The next brake element that used both dissipation mechanisms was designed by Fatzer AG and used by Geobrugg (figure 6b). In this device, the cable is conducted through a protective pipe in a ring shape. An aluminum sleeve acts as a compression element and fastens both ends of the tube. The tension caused by the rockfall on the cable leads to pipe-sleeve friction and the consequent pipe deformation (Grassl et al. 2003). Later, Malla Talud Cantabria developed a brake that changed the ring pipe for two U pipes, and added another compression sleeve (del Coz Díaz et al. 2010). The two compression sleeves connect the two U pipes through their ends (Figure 6c). Tension in the cable makes the pipes slide in the sleeves and deform plastically at the same time. The pressure applied on the aluminum sleeves must be controlled. Otherwise, the same disadvantages as mentioned in the friction brakes section would make these brakes lose part of their dissipation capacity.

The brake in Figure 6d (Trad et al. 2011) consists of a square profile with two plugs at the ends. The cable passes inside the profile several times fastening the plugs in their position. When load is applied on the cable, it presses and rubs both plugs inducing the buckling of the profile with plastic deformation. Thus, the energy dissipation occurs by friction of the cable with the plugs and the tube and plastic deformation due to buckling of the tube. In the same way, the Maccaferri brake (Fig. 6e) is composed of two steel tubes and two rigid perforated plugs at the ends. Two cables coming from opposite directions pass through the tubes and are fixed in the plugs. When a rock impacts on a flexible barrier, the load transmission makes the plugs press against the tubes, generating buckling in the tube, with plastic (hence non-recoverable) deformation. In this brake the friction occurs between the tubes and the cables. In brakes by buckling, especially in those which have square profiles, cracking could appear at the edge area, since this is the most affected by the deformation when generating the folds.

The most recent mixed brakes consist of two steel bars that bend around a mandrel forming a U shape (Figure 6f). When a block impacts on the barrier, the bars displace $180^{\circ}$ around the mandrel absorbing energy by friction and plastic deformation. At the end of the bars an element is placed widening the section, avoiding the discontinuity of the structure if the bars move all the way through the mandrel (Escallón et al., 2014). A variant of this brake substitutes the two bars by a metal sheet which performs the same function. These two brakes are light, making their installation and substitution easier than others which are more voluminous.

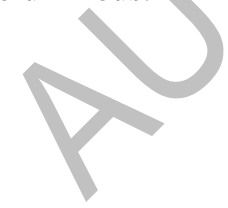



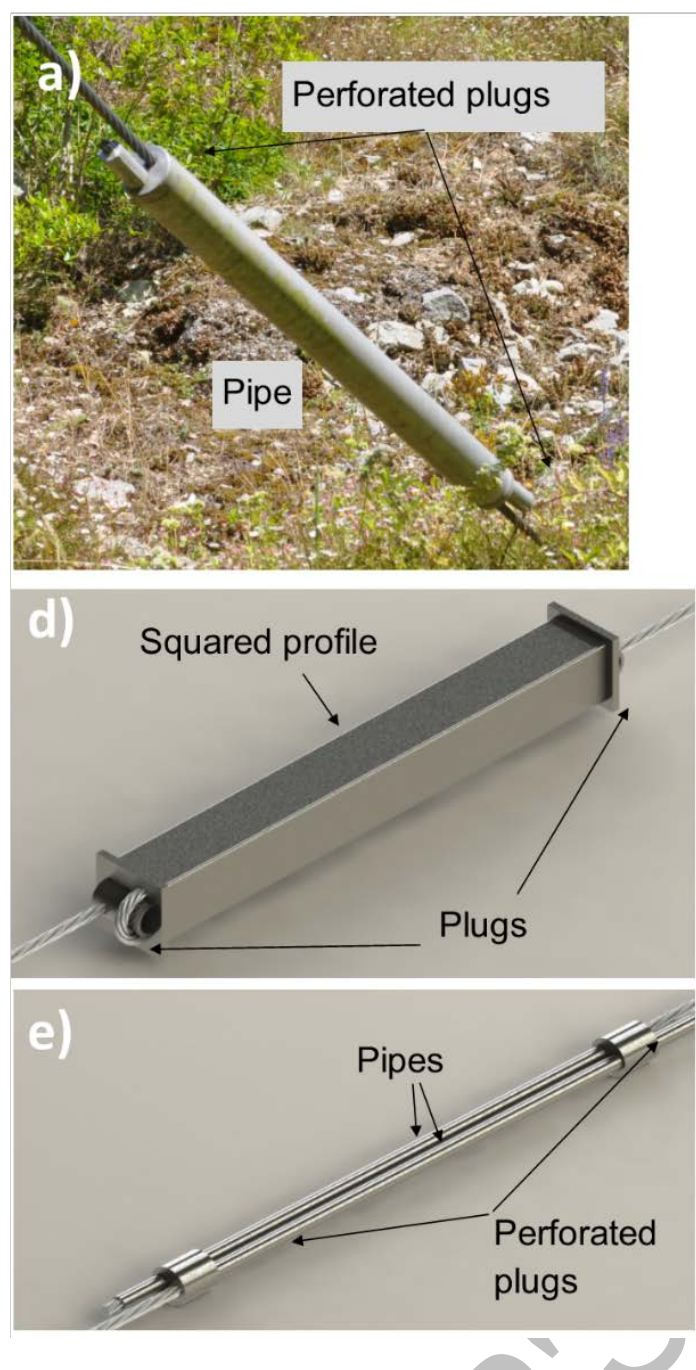

Fig. 6. Mixed brake elements: a) tube (Tubosider), b) ring (Fatzer AG), c) double tube in U (Malla Talud Cantabria), d) square profile type (G.T.S.), e) double tube type (Maccaferri), f1) bars + mandrel (Geobrugg) and f2) steel plate + mandrel (Geobrugg).

\section{Design}

Due to the different geometries and dissipation methods of the brakes, their design method is not standardized as happens with other barrier components, like ties (EN 13411-5) or ground anchors (EN 1537).

With the evolution of flexible barriers, several national and European guidelines were developed (NFP95308 1996, Gerber 2001, EOTA 2008, Peila et al. 2009) that explain the procedure in full-barrier testing and establish the technical assessment of the fitness for use of this product. Only the ETAG 027 (EOTA 2008) gives recommendations for brakes, suggesting the performance of a quasi-static test in a tensile machine at $2 \mathrm{~mm} / \mathrm{s}$ speed and establishing a maximum elongation of 1 meter. This value of elongation is the only design restriction, and it is correctly fixed to limit the maximum lowering of the barrier.

The absence of standardized methodologies for barrier design leaves the way open for manufacturers to choose the number, arrangement and absorption capacity of the brakes.

There are three suitable places to install the brakes: lateral wire ropes, upslope wire ropes and perimeter wire ropes (Fig. 7). In high energy barriers brakes are placed in series. This setup is not certified by the ETAG and maximum elongation of $1 \mathrm{~m}$ must be taken into account. Brake elements allow a less stiff behaviour in upslope and lateral wire ropes. Thus, the loading duration in the barrier caused by a rock impact increases and the peak force is reduced. 

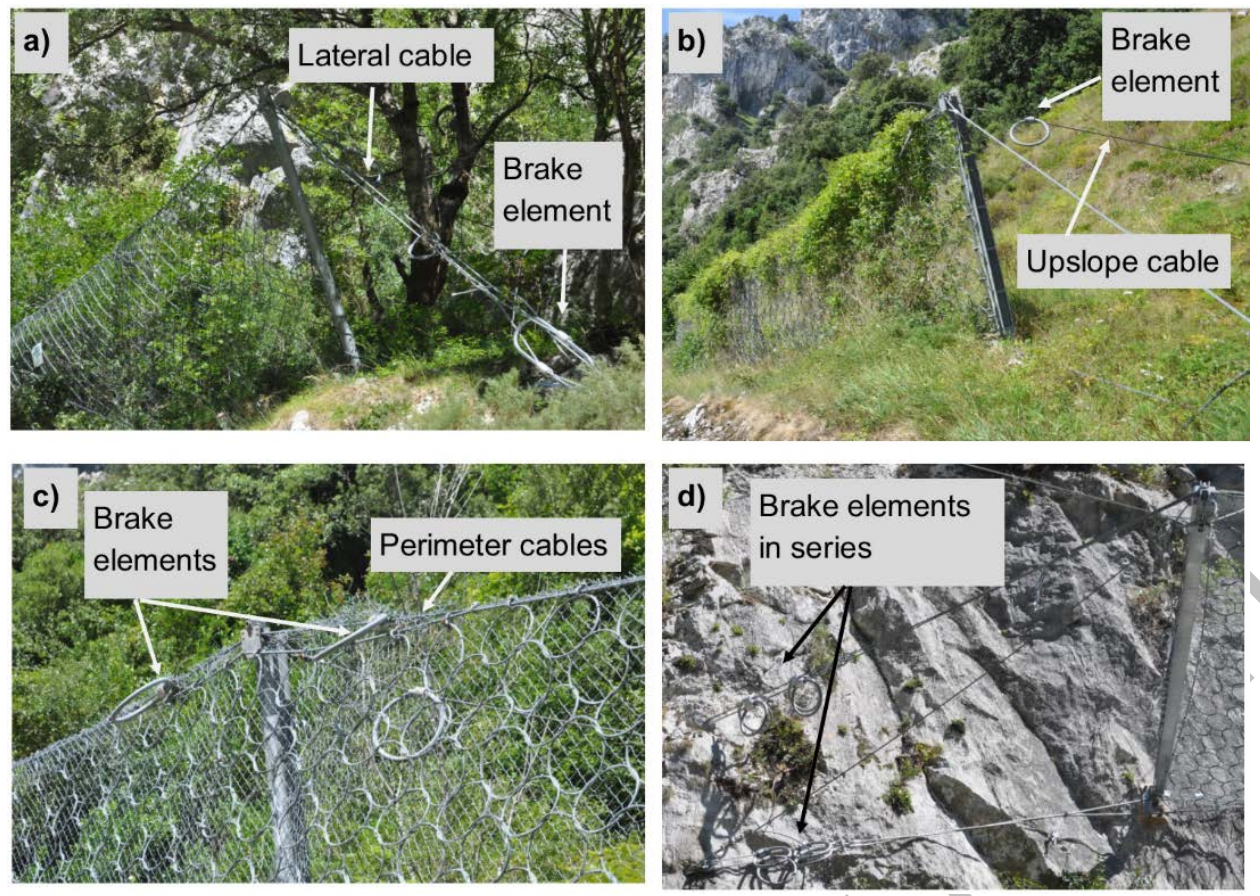

Fig. 7. Installation of brake elements in a) lateral wire ropes, b) upslope wire ropes, or c) in perimeter wire ropes, d) brake elements in series.

Most manufacturers use barrier prototype testing to optimize the number, location and energy level of brakes (Smith et al. 1990). If it is considered that some element does not dissipate enough energy, or on the contrary, if it is oversized, it is substituted by another element considered more suitable for the location in which it is placed. This is an expensive method, although due to the difficulty found in the barrier dynamics, it is the most frequently used one. Therefore, some manufacturers may use numerical simulations using finite element/finite difference software. The numerical model, calibrated by means of the experimental data of their components, can be used as a sizing method, offering illustrative calculations that must be verified by real tests on the full barrier (Gentillini el al. 2013).

\subsection{Design criteria}

When designing a brake, four essential aspects have to be taken into account:

- Integrity

The brakes must be designed to avoid failure when they exhaust their available displacement; that is to say, avoiding their separation into 2 parts. This would cause the failure of the anchorage points in the barrier, leading to instability as well as inefficacy in the rock retention. In some cases, the continuity is guaranteed by incorporating the cable itself into the restraining system where the brake element is fitted (see ring brake in Figure 6b). Moreover, intertwined devices have been designed that avoid their separation (see Malla Talud Cantabria brake in Figure 6c). The installation of protection cables is another solution to prevent collapse (see Pfeifer brake in Figure 5d). In this way, if the brake collapsed, the auxiliary cable would preserve the barrier integrity. Stops at the end of the cable stroke avoid an excessive elongation of the brake, working as a displacement-limiter.

- Adaptability

Versatile brake elements are required, in which parameters such as materials, friction level or friction coefficients among components, dimensions, etc. can vary, generating options regarding their absorption capacity. In the case of brakes that employ a friction mechanism, the two 
components of the friction force -the friction coefficient $\mu$ and the normal force $\mathrm{N}$ - can be varied in order to adapt the brake to the needs of the barrier. The friction coefficient depends on the two materials in contact, and also on the temperature, roughness of surfaces and relative velocity between surfaces. Normal force can vary, changing the pressure between the pieces of the brake in contact. The mechanical properties of the material also affect the energy absorption, providing adaptability to the brakes which work by deformation. Trad (2011) tested brakes in two different materials: steel and aluminum, and concluded that the choice would depend on the energy required by the flexible barrier. Thus, the aluminum brake, with a lower resistance to buckling could be used in a low energy barrier while steel could be used in high energy barriers. The variation of any dimension in a component of a brake makes the force vary and hence, so too the absorbed energy. For example, the greater the thickness of the tubes in the Maccaferri brake (Figure 4a), the higher the opposing force to buckling.

- Durability

Since in most cases brake elements will suffer the harshness of climate, it is important to consider resistance to humidity, corrosion and temperature. One solution to prevent corrosion could be the use of stainless materials or materials with a protective stainless layer. With respect to humidity, there are no studies determining the variability of the behaviour of brakes under rainy conditions. It can be assumed that, when the surfaces of the brake are wet, the friction coefficient decreases and energy dissipation capacity is lower. Furthermore, the fall of any isolated boulder or element from the area must be prevented so that it does not interfere with the brake mechanism negatively affecting its performance.

- $\quad$ Service limit state

It will depend on the number of impacts of different energy, that is, an event on a barrier may make the brakes work only partially, or even not to work at all, so they would be able to resist other events without making any changes in the barrier. Currently, brakes are designed to have a short useful life in relation to the other barrier components, since they are designed as the weakest element of the structure, and are connected in such a way that they are easily replaced.

\subsection{Experimental tests}

The design of a brake element starts by defining its behaviour, by means of the identification of the energy dissipation method. Additionally, characterization of its performance with a force-displacement graph is necessary in order to find out the energy absorption capacity. For this, quasi-static and dynamic tests are performed.
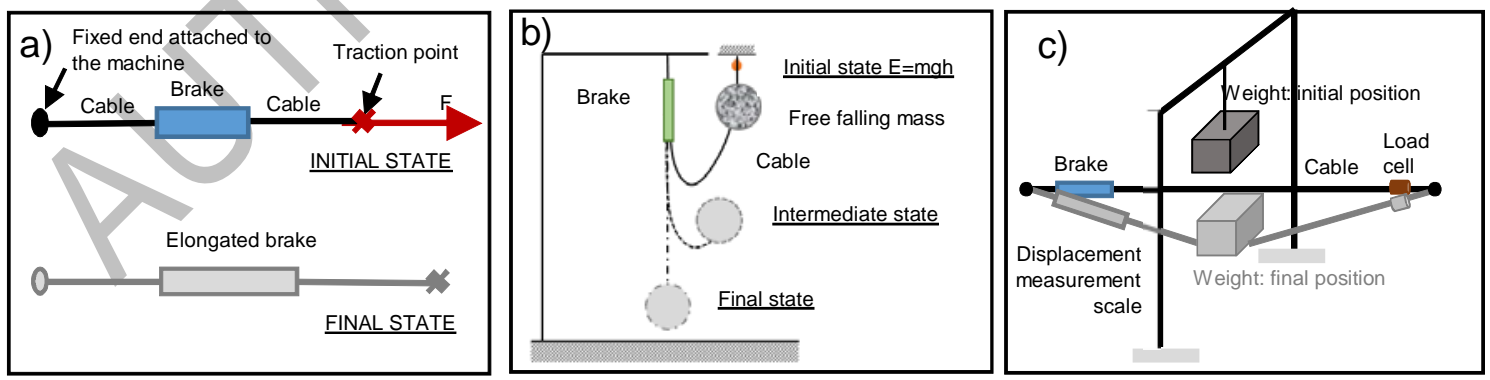

Fig. 8. Scheme of experimental tests in brakes: a) Quasi-static test, b) free falling block: the brake is fixed at one end to the cliff and at the other end to a block, which is dropped from a specific height, and c) impact test: the brake is placed in a horizontal cable and a weight is dropped vertically.

\subsubsection{Quasi-static test}

The quasi-static test consists of fixing one of the cable ends of the brake to a fixed point and pulling on the other cable end using a horizontal traction machine (figure 8a). The applied load values are measured by a 
load cell, and a displacement sensor checks the relative displacement between each of the brake ends. Most companies and researchers have performed quasi-static tests on their brake systems (Smith et al., 1990; Peila et al. 1998; Grassl et al. 2003; Castro-Fresno et al. 2009; Bertrand et al. 2012; Fulde et al. 2013), following the recommendation of the ETAG027. Load-Displacement curves obtained from the quasi-static tests have the same pattern (figure 9). There is a first section where elastic (recoverable) deformation occurs until reaching $\mathrm{F}_{\mathrm{A}}$, corresponding to the activation force of the brake. In Section A-B the absorption mechanisms work. This section may not be linear, but can have different shapes; a zig-zag, wave, increasing or irregular form, depending on the technology of the brake. It tends to have less stiffness than the first branch OA. At the end of the static test, the system (composed of the brake and the cable) behaves like a single cable, corresponding to the hardening branch BC.

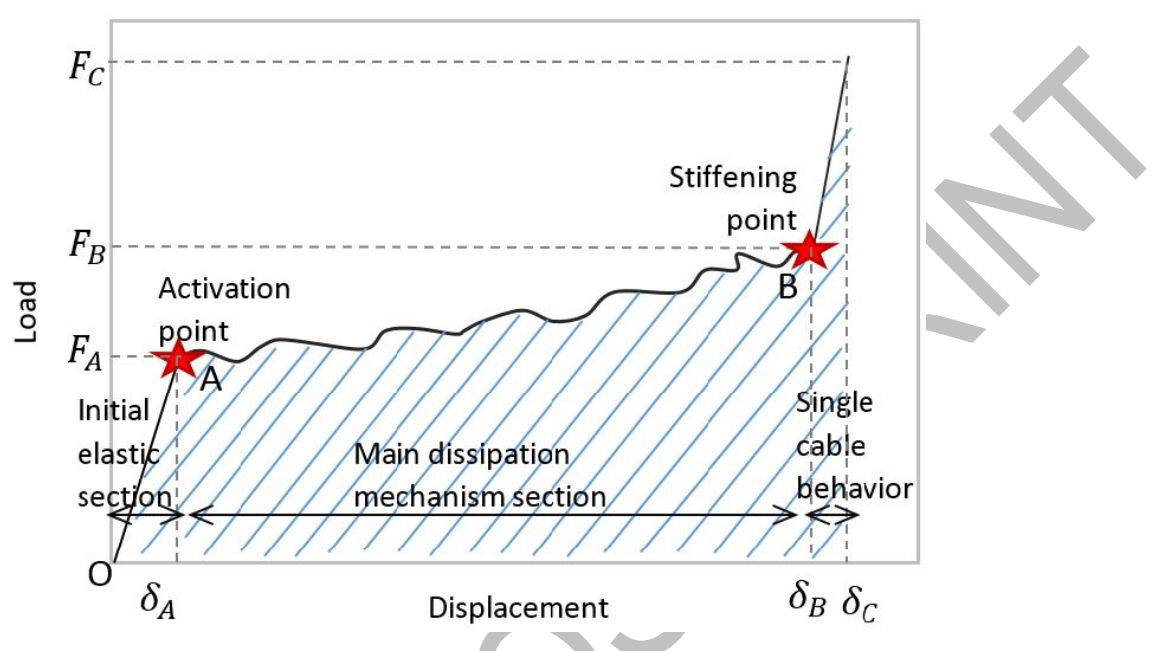

Fig. 9. Typical load-displacement curve from a quasi-static test

A collection of behaviour curves from quasi-static tests of brakes, numbered from 1 to 9 , is presented in Table 1.

For an accurate analysis of brake behaviour, the assumption of the suitability of quasi-static tests suggested by the ETAG027 is not enough, the performance of dynamic tests being advisable. As a demonstration, the full barrier tests carried out by Peila et al. (1998) resulted in no activation of some brakes of the barrier, contrary to what was expected, due to the lack of consideration of the inertia and the load speed in the deformation of brakes.

\subsubsection{Dynamic test (Type 1)}

The development of dynamic tests arose with the aim of approximating more to real conditions. This highspeed system (Bertrand et al. 2012; Trad et al. 2013) consists of fixing one cable end of the brake to a point set at a certain height and joining the other end to a block, which is allowed to fall freely (Figure 8b). By choosing the fall height and block weight, the energy that the brake absorbs can be controlled. Load during all the test is registered by a load cell. The load-time curve is obtained (Table 2). The displacement is only measured at the end, meaning a constant velocity assumption during the whole test, and the intermediate displacements are assumed to be proportional to time. This assumption is not totally adequate, especially in friction processes, where fluctuations are caused by alternating slippage and stop. In this arrangement, results from quasi-static (Force vs Displacement) and dynamic tests (Force vs Time) performed on the same brakes by these authors cannot be directly compared. The analysis of both tests can be only be done by observing the differences in the performance of the brake and the force level of the brake throughout the test. 
Table 1. Behaviour curves of different brakes extracted from quasi-static tests

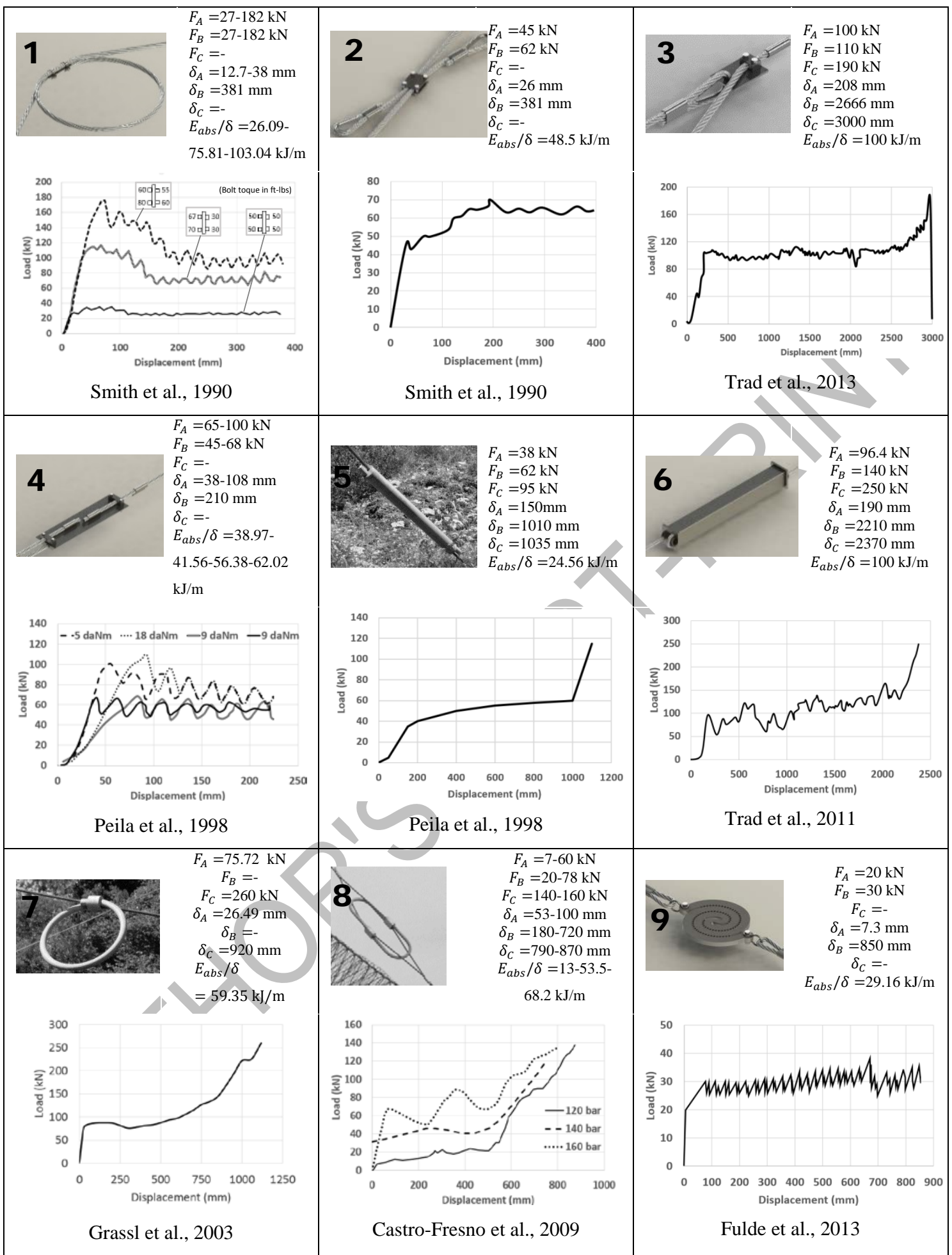

\subsubsection{Dynamic test (Type 2)}

This dynamic test system (Tajima et Al. 2009; Tran et al. 2013a) consists of a brake connected to a horizontal cable anchored at both ends. A weight drops vertically and impacts on the cable (Figure 8c). This event makes the brake work and the load is measured with a load cell. Simultaneously, the increase in length of the cable is observed on a vertical measurement scale. The basic disadvantage of this laboratory test is its complexity. A big structure is needed to hold the weight before the free-falling and a runway also 
needs to be installed in order to attach the cable in its position. Curves obtained from dynamic test type 2 can be seen in Table 2 .

\subsubsection{Dynamic test (Type 3)}

Another way to study the dynamic behaviour of energy dissipaters is carrying out an impact test on a full barrier, registering the force measurement of each brake and observing its performance (Fulde et al. 2013) (Table 2). In order to avoid the interaction of the results, only one brake per cable is recommended. The advantage of this type of tests is that the study of the brake behaviour is at the same speed as under real conditions. The disadvantage is the need for a big infrastructure to perform the tests.

Table 2. Behaviour curves of different brakes extracted from dynamic tests. The first column shows the results from the vertical dynamic test. The data of the second column is extracted from the dynamic test where the set brake+cable

is horizontally fixed and the weight impact is in the vertical direction. The third column corresponds to full-scale barrier tests.

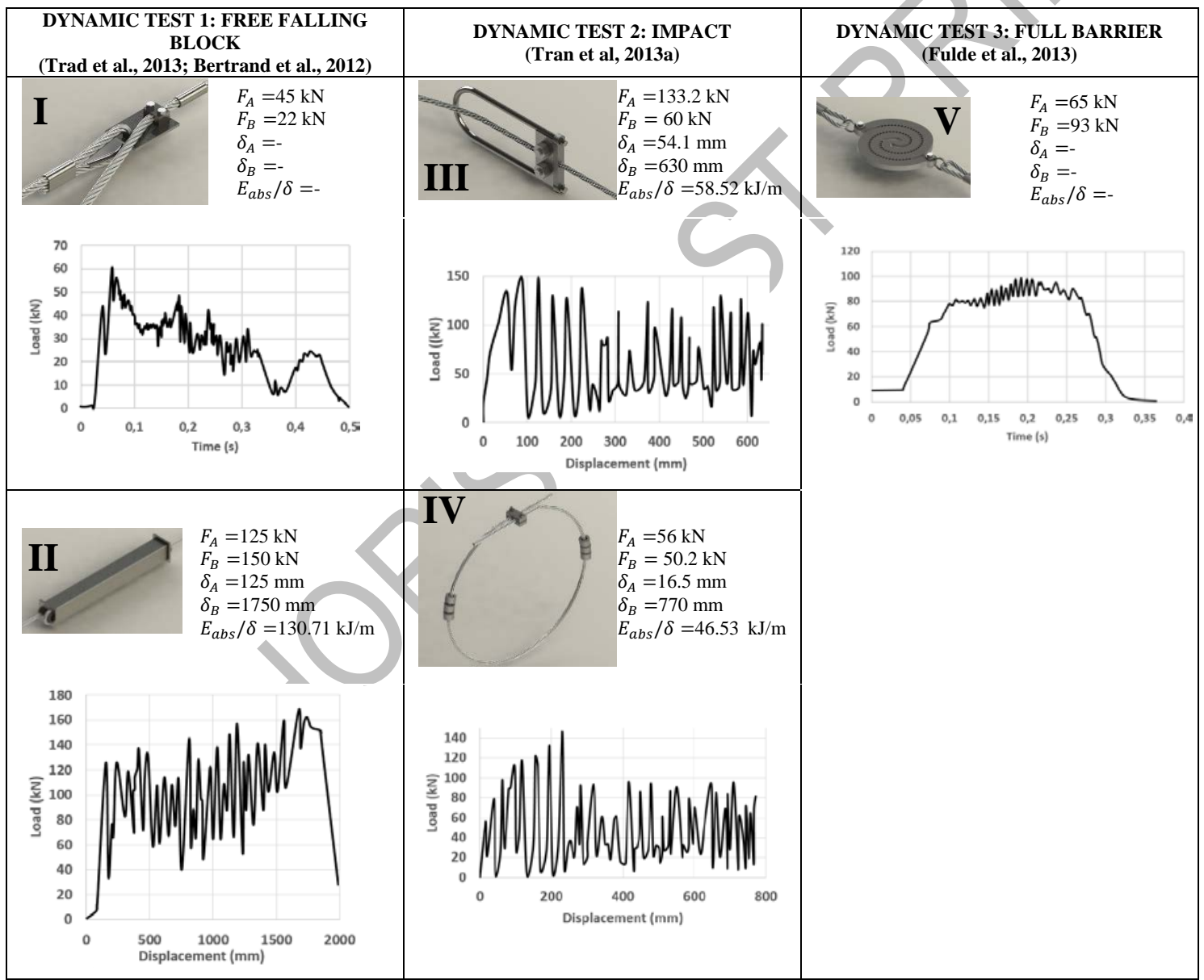

\subsubsection{Behaviour analysis from experimental test data}

Concerning the results from static tests, it can be seen that curves from brakes 1, 2, 4 and 9 in Table 1 do not show a hardening section BC, because the test has been stopped before reaching this situation, bearing in mind that under real conditions the brake should not reach high force values close to the ultimate strength of the cable.

Section $\mathrm{AB}$ has different paths depending on the type of brake. The oscillations in friction brakes (cases 1, $2,3,4$ ) are due to the sequential slippage and stopping of the cables in the clamps. The different curves for 
the same brake correspond to different bolt torques. Force softening in brakes 1 and 4 could be related to the abrasion of the surfaces in contact. Moreover, brake 8 seems to have some waves, due to asymmetric displacement of the $\mathrm{U}$ arms through the compression sleeves. Fluctuations in brake 6 are a consequence of the plastic deformation due to local buckling of the square profile (Trad. 2011). The sawtooth curve of brake 9 is generated by the sequential plastic deformation until failure of the material between the holes (Fulde et al. 2013).

The elastic section OA is missing in one curve of brake 8 (corresponding to the brake with a sleeve pressure of 140 bar). This is due to the initial load applied on the brake before the beginning of the static test to help the brake to accommodate to the machine clamps. The measurement of displacements begins after this accommodation, so the curve displayed has a non-zero initial load.

Force and displacement data at the activation and stiffening points are shown in Table 1 and Table 2, as well as the ratio between absorbed energy and maximal displacement. The absorbed energy is calculated by integrating the area under the Force-Displacement curve and removing the elastic component at the end of the test:

$$
E_{a b s} / \delta=\frac{\int_{0}^{\delta_{\max }} F \cdot d \delta-\frac{F_{C}^{2} \cdot \delta_{A}}{2 F_{A}}}{\delta_{\max }}
$$

As can be seen in brakes 1,4 and 8 , the bolt torque or the sleeve pressure affects the ratio $E_{a b s} / \delta$ to a great extent.

A quantitative analysis of the brakes is not possible due to the differences in: the nature of the load applied in the tests (static or dynamic), the characteristics of the cables in which they are inserted and the geometric differences among the brakes. Hence, a qualitative analysis will be performed and normalized graphs are presented to show the different responses in brakes with the same energy dissipation mechanisms (Figure 10, Figure 11).

Activation forces $\left(\mathrm{F}_{\mathrm{A}}\right)$ of the brakes in Table 1 are analyzed in Figure 10 in a non-dimensional way. $\mathrm{F}_{\mathrm{A}}$ can vary in a similar brake type as occurs in most of the friction brakes, where bolt torque is a parameter that can change the pressure between the surfaces in contact and, hence, the whole behaviour curve. In order to avoid a risk situation, the activation force should not be close to the breaking load of the cable, especially in brakes where friction is incorporated in the dissipation method (friction and mixed). If the activation force of a brake is close to the breaking load of the cable and pressure in friction brakes is not applied accurately, the brake will suffer an elastic behaviour response until the rupture of the cable, and it would not accomplish its dissipation goal.

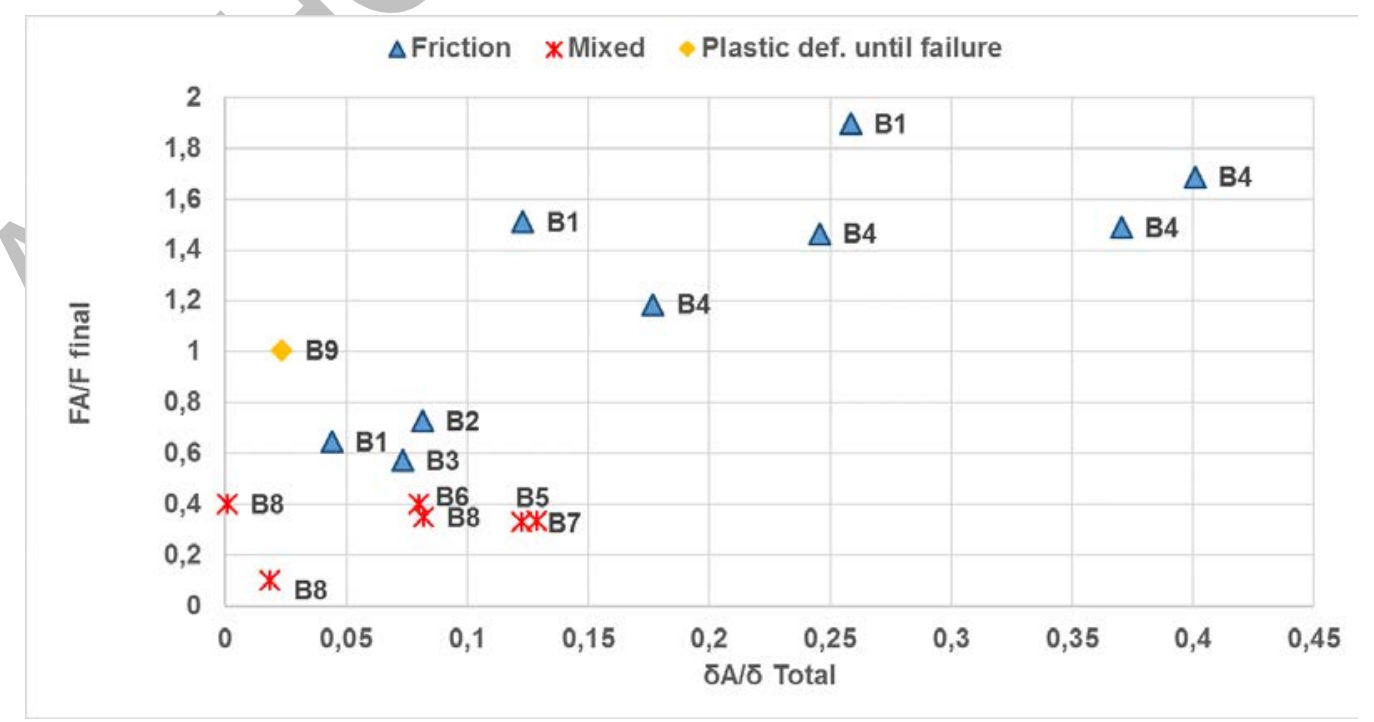

Fig. 10. Non-dimensional analysis of activation point A in Table 1 in terms of the ratio of activation force and final force and the ratio of activation displacement and total displacement. 
The effect of the decrease in the force after the activation of the brakes 1 (B1) and 4 (B4) can be observed in Figure 10, the activation force being the maximum of the curve, and the final force being between 20 and $90 \%$ less than $\mathrm{F}_{\mathrm{A}}$. Mixed brakes have the lowest quotient $\mathrm{F}_{\mathrm{A}} / \mathrm{F}_{\text {final }}$, and the partial failure brake $\mathrm{B} 9$ has a quotient $\mathrm{Fa} / \mathrm{F}_{\text {final }}$ equal to one as the mean force of the A-B section is horizontal.

Differences in the maximum force tolerated in Table 1 may be due to the characteristics of the cables: diameter, configuration of the strands, number of strands, and type of steel.

Continuing the dimensionless analysis, two parameters $\mathrm{E}^{*}$ and $\delta^{*}$ are proposed. $\mathrm{E}^{*}$ is defined as the ratio of the energy of the brake and the maximum value of the brake's energy at the end of the test, and $\delta^{*}$ is the ratio of the elongation of the brake and its maximum value of elongation:

$$
\begin{gathered}
E^{*}=\frac{\int_{0}^{\delta} F \cdot d \delta}{\int_{0}^{\delta \max } F \cdot d \delta} \\
\delta^{*}=\frac{\delta}{\delta_{\max }}
\end{gathered}
$$

These two parameters are related in Figure 11.
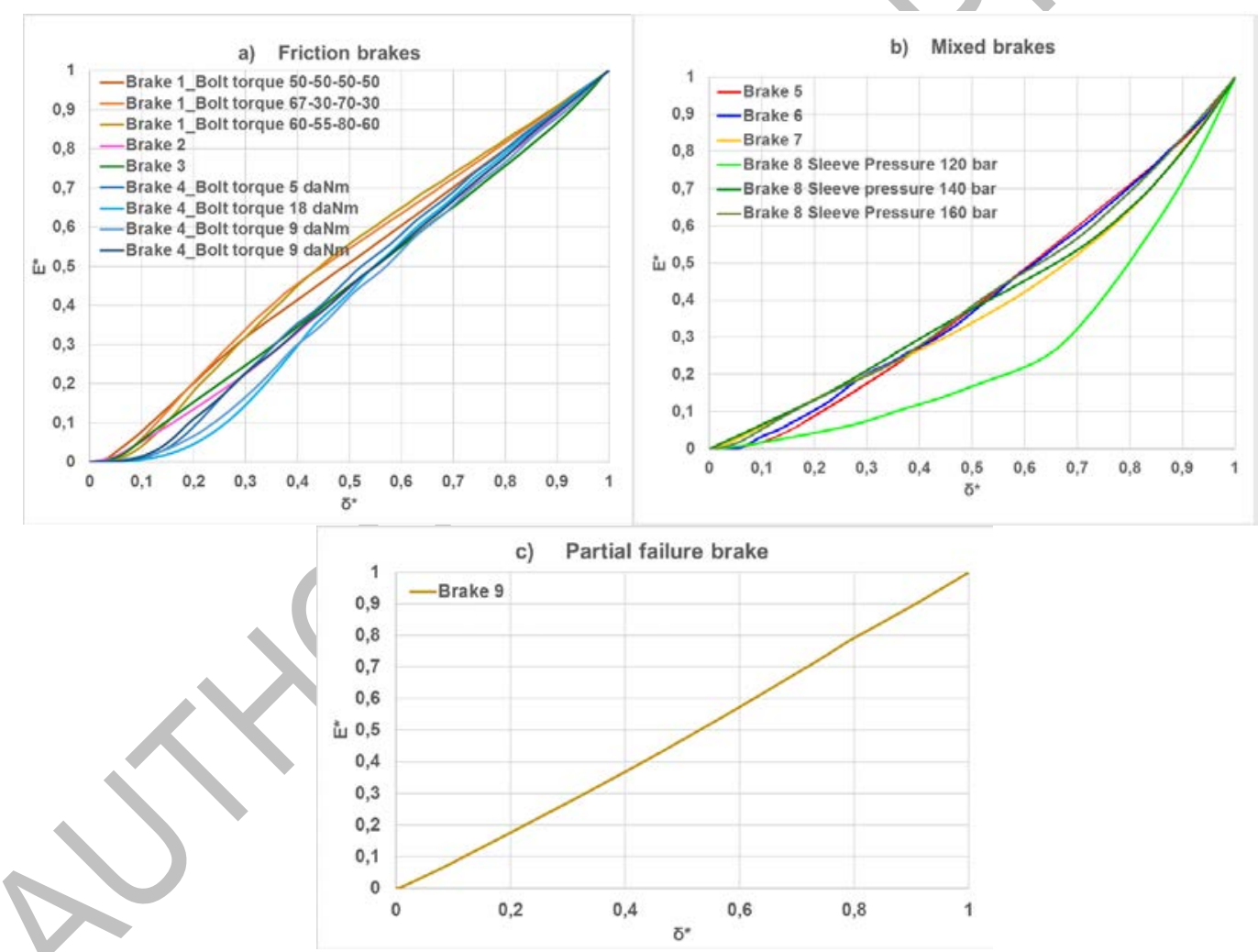

Fig. 11. E* versus $\boldsymbol{\delta}^{*}$ grouped by their dissipation method: a) friction brakes (from 1 to 4 ), b) mixed brakes (from 5 to 8) and c) partial failure brake (9).

In all the curves in Figure 11, there is an initial quasi-horizontal section, corresponding to the initial behaviour of the brakes with a low increment in deformation and high increment in load that demonstrates low elastic energy and hence, a low increment in $\mathrm{E}^{*}$. After this small section, sometimes invisible due to their low displacement percentage of the total, absorbed (non-recoverable) energy appears with a higher slope. A straight slope means a constant increment in energy during the working of the brake, as can be seen in brake 3 until $\delta^{*}=0.9$, in brakes 4 with a torque of 9 daNm and in brake 9 . Other brakes show two successive decreasing slopes, meaning a first part with a higher increment in the proportion of energy absorbed than the next as happens in brakes type 1 and in brake 4 with 18 daNm of torque. Finally, two 
successive increasing slopes mean that at the end of the brake working, it has a higher increment in absorbed energy than at the beginning. This happens in all the mixed brakes, this behaviour being more pronounced in brake 8 with a pressure of 120 bar.

The performance of dynamic tests has a great relevance in order to evaluate the differences in the behaviour of a brake due to inertia and load speed. These two dynamic variables were not considered by Peila et al. (1998); as a result, an unexpected behaviour was obtained, reflected in the non-activation of some of the brakes in the barrier tests.

At this juncture, Trad et al. (2013) performed both types of tests on a friction brake (figure 3d) and on a mixed friction deformation brake (Figure 6d) (first column in Table 2). Although displacement was not measured in the dynamic test, a comparison among forces in both processes was made, with totally different results. Activation force in the pure friction brake reduced $50 \%$ and from that point, force did not remain constant, as happened in the static case, but decreased. Dynamic test type 2 performed on friction brakes (second column in Table 2) also shows a reduction in the amplitude of the peaks at the end. However, in the deformation brake ( $\mathrm{n}^{\circ} 6$ in Table 1 and II in Table 2), activation force and mean force in the operational section were similar in both tests.

The differences in the friction brakes may be due to the wear of the pressure pieces or the dilatation of the material due to the rising temperature in the friction area. It can be concluded that friction brakes are highly sensitive to speed variation. This is coherent with the results of Peila et al. (1998) who used friction brakes in his study. It cannot be stated that tests on other brakes with a different dissipation mechanism will not be affected by dynamic variables, so a dynamic test must be performed in any case. In brakes working by deformation of any of their components (section 2.2 and 2.3), the strain rate effect affects the stress values so the materials mechanical properties could vary with the process dynamics and the Force-Deformation curves could also be sensitive to the test speed. The logical next step is to find out if changes in the speed of the dynamic tests, maintaining the same absorbed energy, can also make the brakes behaviour vary. If this hypothesis is verified, dynamic tests should be done at the same speed as in the barrier.

The measurement of the elongation in the brake must also be registered in the dynamic test. The supposition made by Trad et al (2013), where a linear relationship between displacement and time is assumed, was discarded by Tajima et al. (2009), who demonstrated that in the last instant of the test the elongation-time curve flattens; that is, the speed is not constant.

\subsection{Numerical simulations}

Concerning the research and development of brakes, Finite Element Method (FEM) software is commonly used to help engineers to design and optimize their geometry, as well as to find out what the suitable places in the barrier are to locate brakes. During the energy dissipation of a brake there are several phenomena which affect the setup of the simulations: the brakes suffer large displacements, as can be seen from the curves in Table 1; abrupt-changing interactions in friction brakes as a consequence of the sliding process; and plasticity of materials as a dissipation method in deformation and mixed brakes. These three non linearities can be confronted using both implicit and explicit algorithms. However, explicit analysis is preferred due to the reduction in the computational cost in high-speed dynamic problems (Sun et al. 2000).

Two ways of dealing with the simulation of brakes can be established, depending on the objective of the simulation.

The first concerns the improvement of the geometrical design, optimization of shape and dimensions and the analysis of the dissipation mechanisms within the brake. Three-dimensional models are created for this purpose, introducing realistic geometries, material characterization for each part of the brake and contacts between them. These models are focused on the brake, avoiding the place in which they are located and applying loads and boundary conditions directly on both brake ends. The optimization of the design has to be preceded by a calibration of a reference model, from which a parametric study can be done, searching for the maximum absorbed energy. Since each of the parts in the brake is modelled in detail, weak points can be detected and modified in the prototype. The simulations carried out by Castro-Fresno et al. (2009) and Del Coz Díaz et al. (2010) in Ansys software helped to verify the correct performance of the brakes 
(B8), obtaining energy absorption values very similar to the results of the experimental tests. Several solutions to improve the brake geometry arose and efficient sleeve pressure was established. Likewise, Trad et al. (2013) performed, in CAST3M software, a study of the optimal thickness, length and material of a square profile, employed as the main part of a brake design.

The second way of dealing with a simulation takes into account the behaviour at the scale of the complete structure, achieving a cost-effective method for the study of the barrier optimization. When a flexible barrier is simulated in FE software, the large amount of elements and the non linearities such as plasticity of materials or interactions require large computational cost to solve the problem. Thus, a simpler onedimensional model of the brake should be implemented. The properties of the simplified brake vary depending on the software and author, and they are summarized in Table 3. Axial connectors and truss elements are effectively used for modeling the brake. Few differences exist between these two approaches. In an axial connector, the relative displacement is measured along the connector axis, and the local coordinate system rotates as the nodes change position. Truss elements transmit force axially only and are 3-DOF elements, which allow translation only and do not permit rotation and resistance to bending.

The main differences are the following: cross sectional area is required for trusses, and their behaviour is defined by a stress-strain law; on the contrary, axial connectors are not meshable and they are controlled by a force-displacement law.

The cases compiled in Table 3 use one of the four experimental procedures explained in section 3.2 (quasistatic test, dynamic test 1 , dynamic test 2 or full-scale test).

Usually, when incorporating the 1D element in the full barrier model, it simply consists of interrupting the lateral or upstream cables and placing the truss or the axial connector with a three-linear or four-linear behaviour law (Fig. 12a). However, Dhakal et al. (2011) and Tran et al. (2013) changed this configuration, adding "protection cables" (Fig. 12b). When the stroke of the brake ends, the protection cables, with their corresponding stiffness, begin to work as if a new branch of the graph were defined.

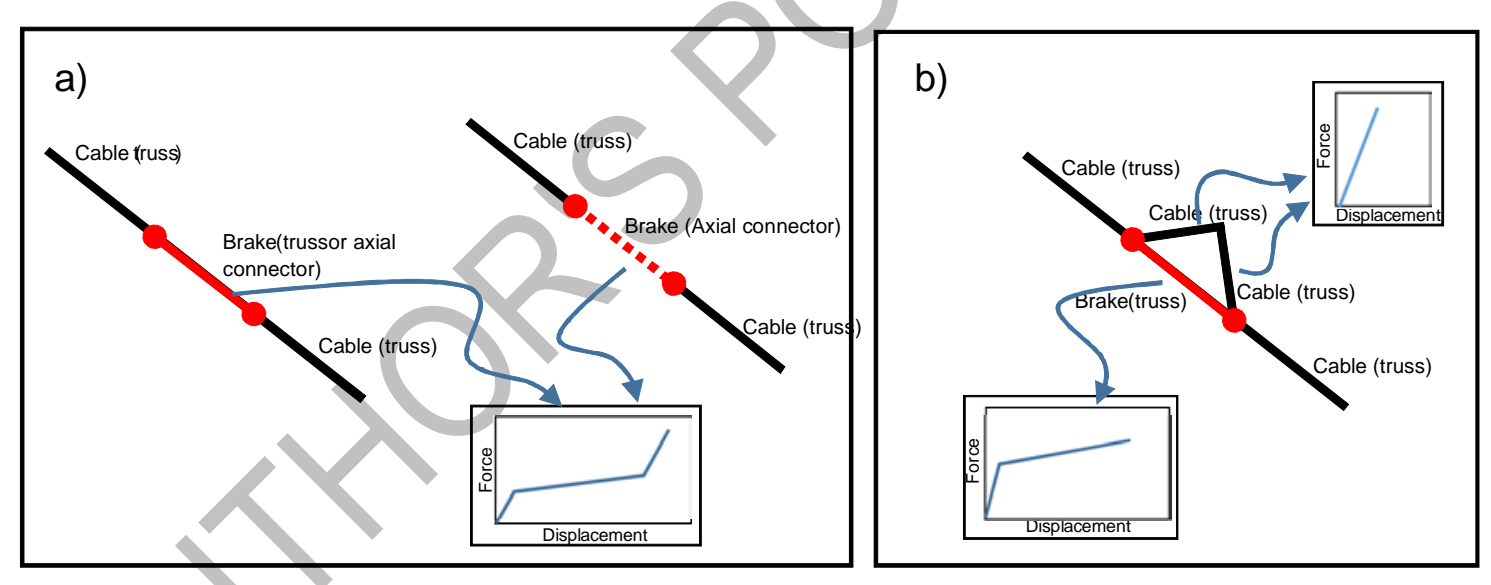

Fig. 12. Configuration of the brakes in the full-scale model: a) single truss or axial connector with a three-linear law, and b) truss brake (bi-linear law) with protection cables.

Both configurations are correct and should have similar results. However, a single $1 \mathrm{D}$ element configuration (Figure 12a) is preferred because of the smaller number of elements, saving computational time.

A hybrid case between the two ways of dealing with a brake simulation is presented by Gentilini et al. (2013), who employed Abaqus to model a 3D brake in static and dynamic conditions, not searching for the optimal design, but looking for the parameters for their use in a 1D model to be included in a full-scale barrier test.

Special mention is required for software based on Discrete Element Method (DEM). DEM programs are based on the motion and interaction of a large number of small particles. Like FEM, DEM has the capacity to solve implicit and explicit algorithms and confront non linearities. Initially, this method was focused on the modeling of granular materials, but nowadays it can be applied in other applications, sometimes 
combined with FEM. Limitations in computational time are similar for both methods: the number of degrees of freedom for FEM and number of particles for DEM.

Nicot et al. (2001) and Bertrand et al. (2012) performed their full-scale simulations by means of DEM models. However, only the latter details the data entered for the definition of the brake. Parameters were extracted from tensile tests under dynamic conditions, and four different approaches were taken depending on the technology of the brake (friction/buckling, elastic perfectly plastic or brittle damageable). Calculations were completed successfully and the three brakes were compared in the context of the full barrier.

Table 3. Brake models in numerical simulations of full-scale barriers.

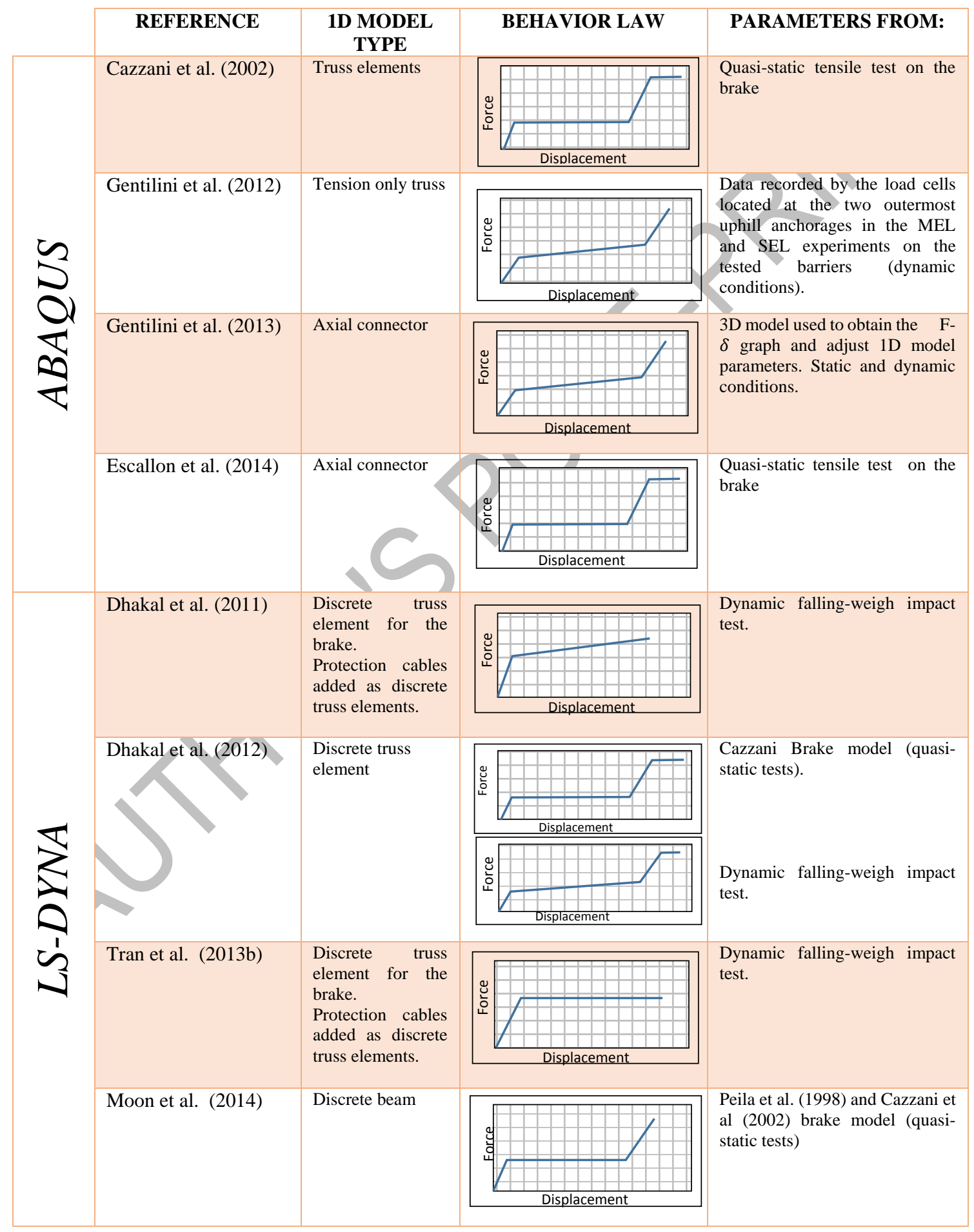




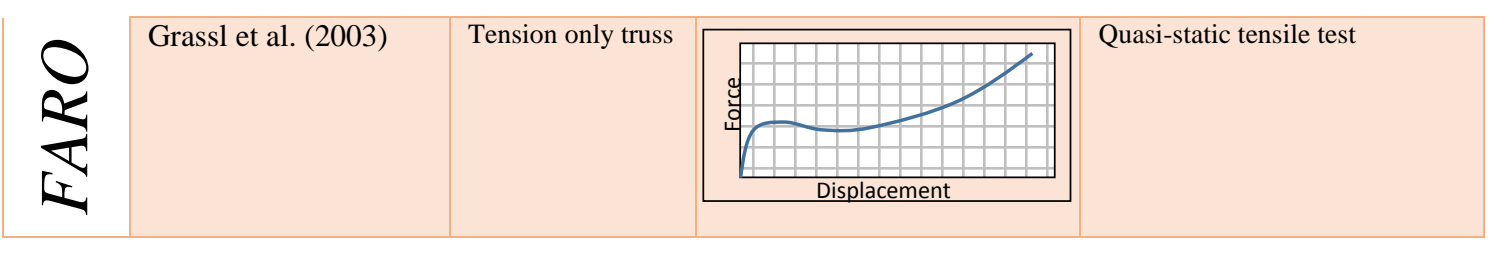

\section{Conclusions}

This paper has offered a classification based on the method used to transform and/or dissipate the energy induced by a rockfall on a cable net. A qualitative analysis was carried out of the behaviour curves from static and dynamic tests. Three different kinds of behaviour were identified; the first has a linear increment in the proportion of absorbed energy during its working, the second has an initial higher increment in the percentage of absorbed energy than in the final part and, the last one, whose percentage of dissipated energy is higher in the final part of the working of the brake. A linear or sequential increasing slope of $E^{*}$ is preferred, since a lower slope of $\mathrm{E}^{*}$ in the final part of the graph means a loss of resistance of the brake.

The amplitude of the peaks in the force-displacement curves due to the slippage and stopping in friction brakes or to local buckling in deformation brakes can be larger with a dynamic behaviour than with the static analysis. Moreover, peak forces can be more than $100 \%$ higher than the activation force. In order to prevent a rupture caused by an unexpected high load peak, an activation force less than $50 \%$ of the rupture force of the cable is recommended for future design processes of brakes.

Further analysis of the variability of friction brakes under wet conditions, like rain or dew, is suggested. Water, acting as a lubricant liquid, may affect the friction coefficient. If this factor has a great influence in the energy dissipation capacity, friction brakes would not be adequate to install in flexible barriers located in rainy or humid places.

Due to differences between low speed and high speed tests regarding activation force and mean operation force, the execution of dynamic tests, more similar to the real conditions of the brake, are preferable over static tests. Trad (2011) performed a large amount of tests with different speeds, materials and energies. However, these three parameters were not studied independently so no conclusions were obtained regarding this topic. The correct analysis should be based on the execution of, at least 9 tests at 3 different speeds ( 3 tests for each speed in order to obtain representative values) maintaining the same absorbed energy; that is, regulating the height of the falling weight. With the aim of clearly observing the differences in the curves (if they exist), the speed values for the tests should be spaced at a minimum of $5 \mathrm{~m} / \mathrm{s}$, choosing, for example, $\mathrm{v}_{1}=10 \mathrm{~m} / \mathrm{s}, \mathrm{v}_{2}=15 \mathrm{~m} / \mathrm{s}$ and $\mathrm{v}_{3}=20 \mathrm{~m} / \mathrm{s}$. The dynamic test configuration can also be improved. The free falling block test does not record displacement measurement over time. The impact test does so; however, the test frame is large and not cost-effective. A new design of tests mixing the simplicity of the free falling block test and the accuracy of the impact test should be developed for the future.

The choice of number and arrangement of the devices in the barrier is an essential aspect to appropriately work and will depend, to a great extent, on the total absorbed energy. In spite of the importance of this point, there is no standardized methodology that defines either the location or the energy level that each brake must absorb to achieve an optimum performance. Measurement of force and displacement in each brake of the full-barrier test is recommended for future analysis, observing whether the brakes behave in the same way as was determined by static and dynamic "only-brake" tests and obtaining the energy level reached and the percentage of energy dissipated. This information was not obtained in any full-scale test and it is considered essential for design optimization. Force measurement can be done with cable sensors, like those used by Blanco et al. (2013), which are able to take the data without cutting the cable.

Several finite element and discrete element software packages are employed as a support tool in the design process. Three-dimensional models help geometry optimization, and one-dimensional brake models are implemented in the analysis of the full barrier with the aim of verifying the suitability of the position and energy capacity of brakes. The behaviour law in 1D models is obtained with static tests in most cases. The reason could be the information provided in the last (and stiffer) part of the curve, which is not obtained 
with dynamic tests. The main suggestion in this aspect is the correction of activation force and mean force if they are different from the static ones.

\section{Acknowledgements}

To Inchalam Bekaert for financial support.

To Malla Talud Cantabria for the information provided.

\section{References}

Bertrand D, Trad A, Limam A, Silvani C (2012). Full-scale dynamic analysis of an innovative rockfall fence under impact using the discrete element method: From the local scale to the structure scale. Rock Mech Rock Eng, 45(5), 885-900. doi: 10.1007/s00603-012-0222-5

Blanco-Fernandez E, Castro-Fresno D, Del Coz Díaz JJ, Díaz J (2013) Field measurements of anchored flexible systems for slope stabilisation: Evidence of passive behaviour. Eng Geol, 153, pp. 95-104. doi: 10.1016/j.enggeo.2012.11.015

Castro-Fresno D, Del Coz Díaz JJ, Garcia Nieto PJ, Norambuena Contreras J (2009) Comparative analysis of mechanical tensile tests and the explicit simulation of a brake energy dissipater by FEM. International Journal of Nonlinear Sciences and Numerical Simulation, 10 (8), pp. 1059-1085.

Cazzani A, Mongiovì L, Frenez T (2002). Dynamic finite element analysis of interceptive devices for falling rocks. Int J Rock Mech Min Sci, 39(3), 303-321. doi: 10.1016/S1365-1609(02)00037-0

Chen Y, Li J, Ran L (2013) A review of rockfall control measures along highway. Applied Mechanics and Materials, 353-356:2385-2391. doi: 10.4028/www.scientific.net/AMM.353-356.2385

de Miranda S, Gentilini C, Gottardi G, Govoni L, Mentani A, Ubertini F (2015) Virtual testing of existing semi-rigid rockfall protection barriers. Eng Struct, 85, pp. 83-94. doi: 10.1016/j.engstruct.2014.12.022

del Coz Díaz J J, Nieto P J G, Fresno D C, Fernández E B (2009). Non-linear analysis of cable networks by FEM and experimental validation. International Journal of Computer Mathematics, 86(2), 301313. doi: $10.1080 / 00207160801965339$

del Coz Díaz J J, García Nieto P J, Castro-Fresno D, Rodríguez-Hernández J (2010). Nonlinear explicit analysis and study of the behaviour of a new ring-type brake energy dissipator by FEM and experimental comparison. Applied Mathematics and Computation, 216(5), 1571-1582. doi: 10.1016/j.amc.2010.03.009

Descoeudres F (1988) Special lecture: stabilizing methods in rock slopes against sliding, toppling or rock falls [Conference speciale: methodes confortatives en versants rocheux contre les glissements, le fauchage ou les chutes de blocs] Landslides. Proc. 5th symposium, Lausanne, 1988. Vol. 2, pp. 821828.

Descoeudres F, Montani Stoffel S, Boll A, Gerber W (1999). Rockfalls. Copying Study on Disaster Resilient Infrastructure. IDNDR Programme Forum 1999 
Dhakal S, Bhandary N P, Yatabe R, Kinoshita N (2011) Experimental, numerical and analytical modelling of a newly developed rockfall protective cable-net structure. Nat Hazards Earth Syst Sci, 11 (12), pp. 3197-3212. doi: 10.5194/nhess-11-3197-2011

Dhakal S, Bhandary N P, Yatabe R, Kinoshita N (2012) Numerical and analytical investigation towards performance enhancement of a newly developed rockfall protective cable-net structure. Nat Hazards Earth Syst Sci, 12 (4), pp. 1135-1149. doi: 10.5194/nhess-12-1135-2012

EN 13411-5:2004+A1:2008. Terminations for steel wire ropes - Safety - Part 5: U-bolt wire rope grips. Brussels.

EN 1537:2015. Execution of special geotechnical works - Ground anchors. Brussels.

Escallón, J P, Wendeler C (2013) Numerical simulations of quasi-static and rockfall impact tests of ultrahigh strength steel wire-ring nets using Abaqus/Explicit. 2013 SIMULIA Community Conference.

Escallón, J. P., Wendeler, C., Chatzi, E., Bartelt, P. (2014) Parameter identification of rockfall protection barrier components through an inverse formulation. Eng Struct, 77, 1-16. doi: 10.1016/j.engstruct.2014.07.019

EOTA (2008). Guideline for the European technical approval of falling rock protection kits. Tech. Rep., European Organization for Technical Approvals (ETAG 27) Feb 2008, Brussels.

Fulde, M., Müller, M. (2013). Development of a modular brake element for the use in modern rockfall catchment fences. 64TH HIGHWAY GEOLOGY SYMPOSIUM, 297-314.

Gentilini C, Gottardi G, Govoni L, Mentani A, Ubertini F (2013). Design of falling rock protection barriers using numerical models. Eng Struct, 50, 96-106. doi: 10.1016/j.engstruct.2012.07.008

Gentilini C, Govoni L, de Miranda S, Gottardi G, Ubertini F (2012). Three-dimensional numerical modelling of falling rock protection barriers. Comput Geotech, 44: 58-72. doi: 10.1016/j.compgeo.2012.03.011

Gerber W (2001). Guideline for the approval of rockfall protection kits. Swiss agency for the Enviroment, Forests and Landscape (SAEFL), Swiss federal research institute WSL, Berne.

Grassl H, Bartelt P A, Volkwein A, Wartmann S (2003). Experimental and numerical modeling of highly flexible rockfall protection barriers. Soil and Rock America 2003, Cambridge, Massachusetts.

López Quijada L (2007). Development and analysis of a dynamic barrier for dissipation of low energy impact as a rockfall protection element, using mathematical models, finite element software and laboratory tests, taking into account dynamic variables. PhD thesis, Universidad de Cantabria, Santander (original source in Spanish).

Moreillon A (2006). European Patent No. 1156158 B1. Lausane. Switzerland.

Moon T, Oh J, Mun B (2014) Practical design of rockfall catchfence at urban area from a numerical analysis approach. Eng Geol, 172, pp. 41-56. doi: 10.1016/j.enggeo.2014.01.004

Muraishi H, Samizo M, Sugiyama T (2005) Development of a flexible low energy rockfall protection fence. Q Rep RTRI 46(3):161-166. doi: 10.2219/rtriqr.46.161 
NFP 95 308:1996. Rock Falling Protection Equipment - Net Trap. AFNOR. France

Nicot F, Cambou B, Mazzoleni G (2001) Design of rockfall restraining nets from a discrete element modelling. Rock Mech Rock Eng, 34 (2), pp. 99-118. doi: 10.1007/s006030170017

Peila D, Oggeri C, Castiglia C (2007) Ground reinforced embankments for rockfall protection: Design and evaluation of full scale tests. Landslides, 4 (3), pp. 255-265. doi: 10.1007/s10346-007-0081-4

Peila D, Pelizza S, Sassudelli F (1998). Evaluation of behaviour of rockfall restraining nets by full scale tests. Rock Mech Rock Eng, 31(1), 1-24.

Peila D, Ronco C (2009) Technical Note: Design of rockfall net fences and the new ETAG 027 European guideline. Nat Hazards Earth Syst Sci, 9 (4), pp. 1291-1298.

Schellenberg K, Vogel T (2009) A dynamic design method for rockfall protection galleries. Structural Engineering International: Journal of the International Association for Bridge and Structural Engineering (IABSE), 19 (3), pp. 321-326. DOI: 10.2749/101686609788957928

Smith D, Duffy J (1990). Field test and evaluation of rockfall restraining nets, final report. California Department of Transportation Materials and Research. USA.

Sun J S, Lee K H, Lee H P (2000).Comparison of implicit and explicit finite element methods for dynamic problems. Journal of Materials Processing Technology, 105(1-2), pp 110-118, doi: 10.1016/S09240136(00)00580-X

Tajima T, Maegawa K, Iwasaki M, Shinohara K, Kawakami K (2009) Evaluation of Pocket-type Rock Net by Full Scale Tests. IABSE. doi: 10.2749/222137809796088846

Thomel L (1998). European Patent No. 0877122 A1. Juan les Pins. France.

Trad A (2011). Analyse du Comportement et Modélisation de Structures Souples de Protection: le cas des Ecrans de Filets Pare-Pierres sous Sollicitations Statique et Dynamique. PhD thesis, Institut National des Sciences Appliquées de Lyon.

Trad A, Limam A, Robit P (2011). Real Scale Experiments on Rockfall Protection Barriers. Applied Mechanics and Materials, 82, pp. 734-739. doi: 10.4028/www.scientific.net/AMM.82.734

Trad A, Limam A, Bertrand D, Robit P (2013). Multi-scale analysis of an innovative flexible rockfall barrier. Rockfall engineering, pp. 303-342. doi: 10.1002/9781118601532.ch9

Tran P V, Maegawa K, Fukada S (2013a) Experiments and Dynamic Finite Element Analysis of a WireRope Rockfall Protective Fence. Rock Mech Rock Eng, 46(5), 1183-1198. doi: 10.1007/s00603012-0340-0

Tran P V, Maegawa K, Fukada S (2013b) Prototype of a wire-rope rockfall protective fence developed with three-dimensional numerical modeling. Comput Geotech, 54, pp. 84-93. doi: 10.1016/j.compgeo.2013.06.008

Verbeke F (2015). Energy dissipators in dynamic screens for rock retaining. Inchalam Bekaert Technical Report

Volkwein A, Gerber W (2011a). Stronger and lighter - evolution of flexible rockfall protection systems. In: IABSE-IASS 2011 London Symposium Report: Taller, Longer, Lighter. Meeting growing demand 
with limited resources. The 35th Annual Symposium of IABSE. The 52nd Annual Symposium of IASS and incorporating the 6th International Conference on Space Structures. Zürich, IABSE. 5

Volkwein A, Schellenberg K, Labiouse V, Agliardi F, Berger F, Bourrier F, Dorren L K A, Gerber W, Jaboyedo M (2011b) Rockfall characterisation and structural protection - A review. Nat Hazards Earth Syst Sci, 11:2617-2651. doi: 10.5194/nhess-11-2617-2011

Von Allmen H P (2004) European Patent No. 1469130 A1. Tafers. Switzerland. 